\title{
Climatic adaptation of Drosophila buzzatii populations in southeast Australia
}

\author{
P Sarup $^{1}$, JG Sørensen ${ }^{1}$, K Dimitrov ${ }^{1,2}$, JSF Barker ${ }^{3}$ and V Loeschcke ${ }^{1}$ \\ ${ }^{1}$ Aarhus Centre for Environmental Stress Research (ACES), Department of Ecology and Genetics, University of Aarhus, Ny Munkegade, \\ Buildg. 540, DK-8000 Aarhus C, Denmark; '2Department of Ecology, Faculty of Biology, Sofia University, St Kliment Ochvidski 8, \\ Dragan Tznkov, Sofia 1164, Bulgaria; ${ }^{3}$ School of Rural Science and Agriculture, University of New England, Armidale, NSW 2351, \\ Australia
}

\begin{abstract}
Variation in 19 traits possibly relevant for thermal adaptation was studied in 11 populations of Drosophila buzzatii collected in southeast Australia. Using stepwise multiple regression, the variation was compared to variation in geographic coordinates and to a set of climatic variables estimated for each collection site. For 13 of the traits, a significant part of the variation was explained by climatic variables and/or geographic coordinates, suggesting directional selection for adaptation to the environment in the majority of traits studied. In 10 of the traits, both geographic coordinates and climatic variables explained significant proportions of the variation, with $R^{2}$ ranging from 0.075 to
\end{abstract}

0.58. Although larvae, pupae and adults of $D$. buzzatii share a common habitat, the measured traits were not correlated across life stages and gender. Also, there seemed to be special conditions in marginal populations near species borders, giving rise to nonlinear relations with latitude. Climate apparently does influence the adaptive evolution of the traits studied, but they also are affected by other factors that vary with latitude, longitude and distance to coast. These results highlight the complex challenges imposed by the environment on the adaptive process.

Heredity (2006) 96, 479-486. doi:10.1038/sj.hdy.6800828; published online 12 April 2006

Keywords: latitudinal gradient; heat-shock resistance; thermal adaptation; heat-induced sterility; larval survival; Hsp70 expression

\section{Introduction}

The distribution and abundance of species is for a large part determined by environmental variables of which temperature is generally considered to be one of the most important (Cossins and Bowler, 1987; Hoffmann et al, 2003a). Thus, the study of variation in thermal resistance is relevant when looking for adaptive variation among populations and species. From a biodiversity perspective, thermal resistance also is potentially relevant, as climate is predicted to be even more variable and changing in the near future (IPCC, 2001). In order to persist, species must adapt to, or avoid, stressful conditions imposed by the ever-changing climate. A well-established model system for the study of thermal adaptation is Drosophila buzzatii (Loeschcke et al, 1994; Sørensen et al, 2001, 2003). This cactophilic species is especially well suited to the study of adaptation, because of its well-defined ecology. All life stages live on and in rotting cladodes of Opuntia spp. (Barker and Mulley, 1976), a habitat that is often exposed to high temperatures (Gibbs et al, 2003).

Some studies of thermal resistance focus on resistance at the adult stage, but this gives an incomplete picture of

Correspondence: $P$ Sarup, Aarhus Centre for Environmental Stress Research (ACES), Department of Ecology and Genetics, University of Aarhus, Ny Munkegade, Buildg. 540, DK-8000 Aarhus C, Denmark.

E-mail: pernille.sarup@biology.au.dk

Received 20 July 2005; accepted 6 March 2006; published online 12 April 2006 the thermal resistance of an organism that has four very different life stages, as thermal extremes may not affect all life stages in the same way (Loeschcke and Krebs, 1996). Even the seemingly homogeneous habitat of a rotting cactus cladode can provide very different microhabitats for small organisms such as Drosophila. Sun and shade will alternate and different areas of the rot will offer different degrees of thermal stress (Feder, 1997; Sørensen et al, 2003). The immobile life stages (ie eggs and pupae) cannot actively avoid high temperatures, as can the adults and to a lesser degree the larvae. This means that eggs, pupae and to some degree the larvae may be more exposed to thermal stress than adults and therefore might be a more likely target for thermal adaptation (Krebs and Loeschcke, 1995b). In addition, the different life stages may very well react differently to the same environmental conditions; this also makes it important to study heat resistance in life stages other than the adult.

One tool in the study of thermal adaptation is to compare resistance traits among populations from different geographic regions, which are assumed to differ in thermal characteristics. Most studies have compared a small number of traits in a small number of populations. With only two to three populations studied along a climatic gradient (eg latitudinal), it is difficult to distinguish between real adaptation and random variation (Garland and Adolph, 1994). Davidson's (1990) study of geographical variation in desiccation resistance in $D$. melanogaster exemplifies the problem. The results showed a population from a temperate region to be more resistant than a tropical 
population, but this difference was not consistent when 13 populations from the two regions were compared (Hoffmann et al, 2001). Another important issue for successfully identifying natural adaptation is to investigate resistance traits that are relevant under natural conditions. However, as the thermal environment that Drosophila adults and larvae experience in the field is poorly known, it can be difficult to predict whether natural adaptation should lead to clinal variation in specific stress resistance traits. Local conditions might also disturb the overall pattern of adaptation, especially when only a small number of populations are studied. However, for some traits there is evidence that links climatic variability with variation in stress resistance traits. For example, survival following high temperature heat exposure (Hsp induction) was strongly related to Hsp70 expression, which itself was inversely related to high temperature adaptation in adult D. buzzattii (Sørensen et al, 2001). For heat adaptation, knockdown resistance has been suggested to be important and to correlate with natural adaptation to high-temperature environments (Hoffmann et al, 2002; Sørensen et al, 2001, 2005). In nature, high temperature is correlated with desiccation, but many studies have failed to show clinal variation in desiccation resistance (Hoffmann et al, 2001, 2002), whereas others have found presumably adaptive patterns in desiccation resistance (Karan et al, 1998; Hoffmann et al, 2003b).

The aim of the present study was to identify traits important for thermal adaptation, that is, those showing some kind of clinal variation. We investigated the variation in 19 traits potentially involved in thermal adaptation of $D$. buzzatii. The 11 populations studied were selected on the basis of extensive climatic data to ensure that the sites were maximally different with regard to most climatic variables. Resistance traits in three of the four life stages, larvae, pupae and adult, were studied, with the majority of traits in the larval or adult stage. Several heat-resistance traits and developmental time at 25 and $30^{\circ} \mathrm{C}$ were measured. We found clinal variation in 13 of the 19 traits studied. Ten of these traits were influenced by several of the variables used in the analysis, indicating a complex relationship between geographic coordinates, climatic variables and trait response.

\section{Materials and methods}

\section{Origin and maintenance of flies}

Flies were collected in April 2002 at 11 sites in southeast Australia (Figure 1) - Mulambin Beach $\left(150^{\circ} 47^{\prime} \mathrm{E}\right.$, $\left.23^{\circ} 11^{\prime} \mathrm{S}\right)$; Isla Gorge $\left(149^{\circ} 56^{\prime} \mathrm{E}, 2^{\circ} 15^{\prime} \mathrm{S}\right)$; Big Womalilla Creek (147 $\left.46^{\prime} \mathrm{E}, 26^{\circ} 29^{\prime} \mathrm{S}\right) ; \quad$ Grandchester $\left(152^{\circ} 27^{\prime} \mathrm{E}\right.$, $\left.27^{\circ} 41^{\prime} \mathrm{S}\right)$; Hickey Island $\left(153^{\circ} 21^{\prime} \mathrm{E}, 2^{\circ} 26^{\prime} \mathrm{S}\right)$; Metz (151 $\left.53^{\prime} \mathrm{E}, 30^{\circ} 35^{\prime} \mathrm{S}\right)$; Baradine (149 $\left.04^{\prime} \mathrm{E}, 30^{\circ} 57^{\prime} \mathrm{S}\right)$; Tambar Springs ( $\left.149^{\circ} 57^{\prime} \mathrm{E}, 31^{\circ} 18^{\prime} \mathrm{S}\right)$; Gerongar Point $\left(150^{\circ} 49^{\prime} \mathrm{E}\right.$, $\left.34^{\circ} 33^{\prime} \mathrm{S}\right)$; Maldon (Baringhup) $\left(143^{\circ} 57^{\prime} \mathrm{E}, 36^{\circ} 59^{\prime} \mathrm{S}\right)$; and Bulla $\left(144^{\circ} 46^{\prime} \mathrm{E}, 37^{\circ} 39^{\prime} \mathrm{S}\right)$. These sites were selected from 97 where D. buzzatii had been collected previously (Barker et al, 2005). With the position of a locality described by latitude, longitude and elevation, the BIOCLIM program of the ANUCLIM 5.1 package (Houlder et al, 2000) estimated 35 climatic variables for that locality. Principal component analysis was then

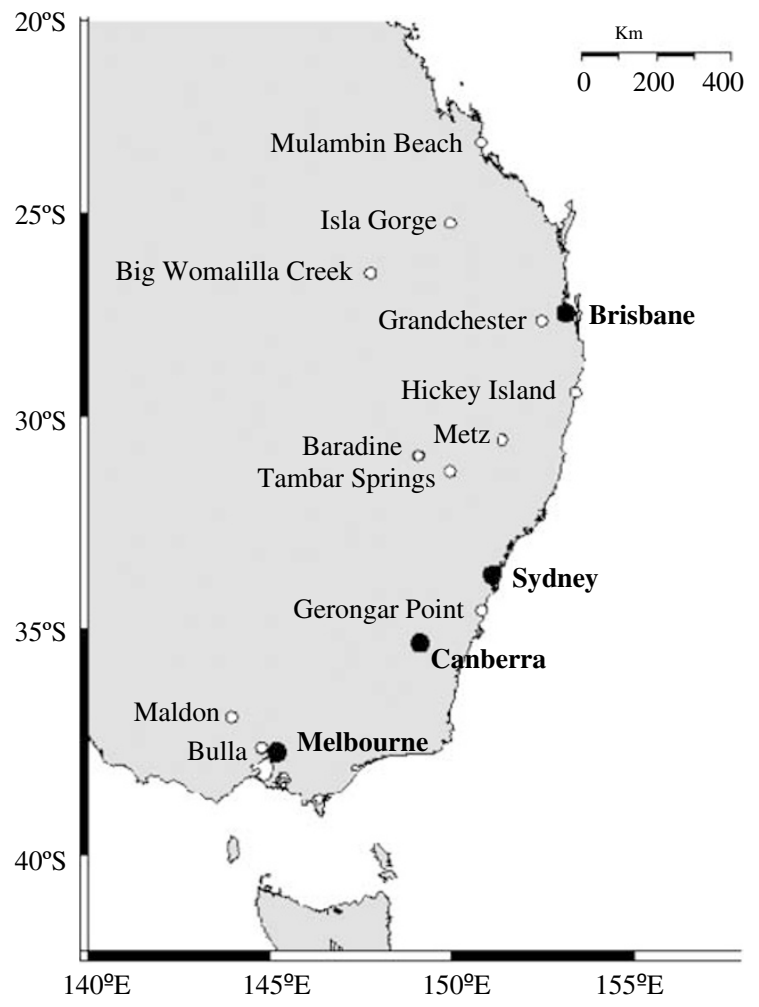

Figure 1 Map of southeast Australia showing the locations where D. buzzatii were collected.

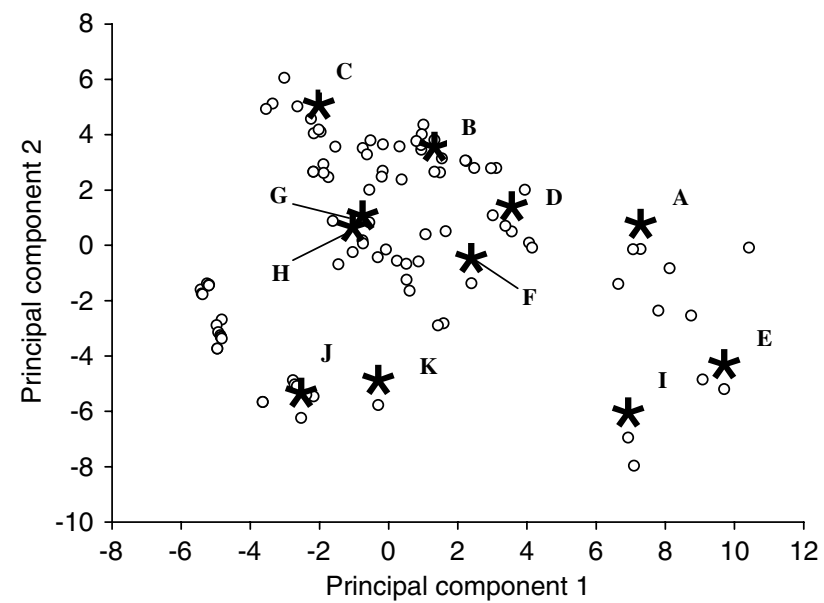

Figure 2 Graphic presentation of the first two principal components from a PCA analysis of 35 climatic variables from 97 known $D$. buzzatii collection sites. The collected populations are marked with stars and letters: A, Mulambin Beach; B, Isla Gorge; C, Big Womalilla Creek; D, Grandchester; E, Hickey Island; F, Metz; G, Tambar Springs; H, Baradine; I, Gerongar Point; J, Maldon; and K, Bulla.

applied to these data for each of the 97 localities (SAS Institute, 1985) to provide a summary of the climatic environment for each. The first PC describes a gradient of increasing precipitation and moisture indices and decreasing temperature variability and radiation. The second component describes a gradient of increasing temperature, precipitation and moisture index season- 
ality, and decreasing moisture indices in the lowest week and quarter, precipitation in the driest quarter and radiation seasonality. Selection of the 11 sites for this study was based on the plot of principal component 1 and principal component 2 (Figure 2), so as to maximise climatic differences among them.

Twelve isofemale lines were established from each population. Each isofemale line was maintained before and during the experiment with approximately 25 pairs in each of two bottles $(200 \mathrm{ml})$ with $14 \mathrm{ml}$ of instant Drosophila medium (Carolina Biological Supply, Burlington, NC, USA). Throughout the experiments, instant Drosophila medium was used, unless stated otherwise. All experiments were conducted within three to 10 generations after collection.

\section{Hsp70 expression}

Hsp70 expression was assayed in larvae, pupae and adult males and females. In all cases, five random isofemale lines from each of the 11 populations were assayed. Hsp induction took place in preheated waterbaths for $1 \mathrm{~h}$ with the water above the bottom of the stoppers, followed by a $1 \mathrm{~h}$ recovery at $25^{\circ} \mathrm{C}$ before freezing at $-70^{\circ} \mathrm{C}$. The vials were placed in racks in preheated waterbaths and spaced evenly to ensure homogeneous heating. Third instar larvae for heat treatment were collected by inserting paper into the bottles and leaving for $6 \mathrm{~h}$. The paper with wandering third instar larvae was then transferred to empty plastic vials with moistened stoppers to prevent desiccation and heated at $37^{\circ} \mathrm{C}$. On another set of papers from different bottles, the larvae were allowed to pupate and then transferred to empty plastic vials on the moist paper. The pupae were heat exposed at $38^{\circ} \mathrm{C}$ 2-3 days after pupation. Adult flies less than $24 \mathrm{~h}$ old were collected, sexed under light $\mathrm{CO}_{2}$ anaesthesia and transferred to food vials at a density of 15 individuals per vial. On day 3 , they were transferred to fresh vials. When flies were 56 days old, they were placed in empty glass vials and heat exposed. To prevent desiccation, the stoppers were in all cases moistened with tap water. For adults, two temperatures were used, 37 and $39^{\circ} \mathrm{C}$. Later, larvae, pupae and adults were homogenised and the level of Hsp70 expression assayed using a monoclonal inducible Hsp70 antibody (7.FB; Velazquez et al, 1980, 1983). Enzyme-linked immunosorbent assay was conducted in five replicate microwell plates following the protocol described in Sørensen et al (1999).

\section{Knock down resistance}

Flies less than $24 \mathrm{~h}$ old from five random lines per population were collected and transferred to food vials at a density of approximately 50 (equal number of both sexes). Every second day, they were transferred to fresh vials. When flies were between 5 and 7 days old, the knockdown test (Huey et al, 1992) was conducted at a constant temperature of $40.0^{\circ} \mathrm{C} \pm 0.1$, as described in Sørensen et al (2001).

\section{Sterility period}

Sterility period was scored after males developed at one of two experimental temperature regimes: 25 and $25^{\circ} \mathrm{C}$ $(18 \mathrm{~h}) / 38^{\circ} \mathrm{C}(6 \mathrm{~h})$. Twenty-five pairs from 12 lines per population were allowed to lay eggs in $200 \mathrm{ml}$ bottles for
$24 \mathrm{~h}$ at $25^{\circ} \mathrm{C}$. Bottles were placed at the appropriate temperature 2 days after the beginning of oviposition, where they remained until emergence of adults. To prevent desiccation of the bottles at the high temperature, a tray with water was placed in the bottom of the incubators and stoppers were wetted every second day.

After hatching, males (0-12 h old) were placed on sugar-agar-yeast medium with 6-day-old virgin females, raised at $25^{\circ} \mathrm{C}$, from their respective population. For each combination of line and treatment, one vial with 10 males and four females was placed at $25^{\circ} \mathrm{C}$. Every $12 \mathrm{~h}$, the flies were transferred to new vials. Vials were kept at $25^{\circ} \mathrm{C}$ and later evaluated for the presence of larvae. Time until sexual maturity was reached, for at least one of the 10 males in a vial, was calculated from the mean of the period where the males eclosed to the mean of the period where the first viable eggs were laid. This measure of heat-induced sterility includes the period where males naturally are sexually immature.

\section{Developmental time}

Developmental time was measured at two experimental temperatures: 25 and $30^{\circ} \mathrm{C}$. From each of 10 random lines from each population, first instar larvae (raised at $25^{\circ} \mathrm{C}$ ) were collected, and 25 transferred to each of two vials. These vials were placed at the temperature regimes of 25 and $30^{\circ} \mathrm{C}$, respectively, and the number of eclosed flies was scored every $12 \mathrm{~h}$. To prevent desiccation of the vials at the high temperature, a tray with water was placed in the bottom of the incubator and stoppers were wetted every second day. Mean developmental time of each sex emerging in each vial, estimated as the mean time from larval collection to adult eclosion, was $\log _{10}$ transformed to give a better fit to the normal distribution.

\section{Heat-shock survival}

Heat-shock survival was assayed in larvae and adult flies. First instar larvae were collected from 10 lines from each population with one replicate/line, and transferred to food vials at a density of 25 larvae/vial. The larvae were kept at $25^{\circ} \mathrm{C}$ until heat shocked. Two experimental groups were used and a control was kept at $25^{\circ} \mathrm{C}$ throughout the development. At day 4 after collection, one group was hardened for $1 \mathrm{~h}$ at $37^{\circ} \mathrm{C}$ followed by $2 \mathrm{~h}$ recovery at $25^{\circ} \mathrm{C}$ before being heat shocked at $42^{\circ} \mathrm{C}$ for $1 \mathrm{~h}$. The other group was placed directly at $40.5^{\circ} \mathrm{C}$ for $1 \mathrm{~h}$. After heat shock, the larvae were returned to $25^{\circ} \mathrm{C}$ for development and survivors were scored as number of eclosing flies.

Adult flies less than $24 \mathrm{~h}$ old were collected from eight lines per population, set up (sexes separate) at a density of 20 per vial, and heat shocked according to the protocol described for Hsp70 expression in adults. One group was hardened at $37^{\circ} \mathrm{C}$ for $1 \mathrm{~h}$, followed by $1 \mathrm{~h}$ at $25^{\circ} \mathrm{C}$ to allow the flies to recover before being heat shocked for $1 \mathrm{~h}$ at $41.5^{\circ} \mathrm{C}$. The other group was directly heat shocked at $40.5^{\circ} \mathrm{C}$ for $1 \mathrm{~h}$. After the heat shock, flies were transferred to fresh food vials, which were turned upside down to prevent the flies from getting stuck in the medium, and allowed $24 \mathrm{~h}$ of recovery at $25^{\circ} \mathrm{C}$ before being scored as either alive or dead. Flies were considered as alive if they were able to walk after a light touch with a brush. As survival was calculated as proportions, arcsine-square- 
root transformation was applied to improve normality and homogeneity of variances.

\section{Statistical analyses}

ANOVA was used when appropriate to establish general effects of treatment and sex within experiments using JMP v.5 (JMP, 2002), thereby determining if separate regressions for males and females were necessary. For each trait, effects of geographical location and climate were analysed, with climate characterised by the scores for the first four principal components (PC1, PC2, PC3 and PC4), which accounted for $93 \%$ of the variation.

Latitude, longitude and distance from the coast were recorded for each locality, but as the relationships with latitude and longitude were not necessarily linear, quadratic and cubic terms for these were included. Distance from the coast provides a further coordinate to latitude and longitude for geographical location, and was included because climatological zones in eastern Australia tend to run parallel to the coast (Nix, 1982). That is, localities on the same longitude but at different distances from the coast could be in quite different climatological and ecological regions.

Multiple regression analysis of each trait was carried out using a backwards stepwise procedure to suggest which terms may be required in the final model, using the statistical package R (R Development Core Team, 2003), and its stepwise procedure, STEP. For adding and deleting terms, this procedure uses the Akaike Information Criterion (Akaike, 1974), which is based on loglikelihood but also takes into account the number of parameters fitted. If two models give similar fits, the model using the least number of parameters is selected. All tests for individual terms were adjusted for other terms in the model of the same or lower order (Type II tests).

\section{Results}

Means and standard errors of all traits in all populations are presented in Table 1 .

\section{Hsp70 expression}

No comparisons of Hsp70 expression level in larvae, pupae, and male and female adults were possible as Hsp70 expression level in each 'Hsp70 expression group' was assayed in different experimental blocks. However, it is possible to compare Hsp70 expression between life stages and sex by correlating Hsp70 expression level in the different groups. After correcting the probability levels by the Dunn-Sidak method (Sokal and Rohlf, 1995), the only two groups that were significantly correlated were Hsp70 expression level in females at 37 and $39^{\circ} \mathrm{C}$ (one-tailed Pearson's correlation; $r=0.76$; $P=0.0034)$.

Within each experimental group, population variation was investigated by multiple regression. For third instar larvae, there was a significant regression with latitude squared $(\beta=0.0002 ; P<0.01)$ explaining $16 \%$ of the variation in $\mathrm{Hsp} 70$ expression between populations (Table 2, Figure 3a). No significant regression was detected for pupal expression level. For females at $37^{\circ} \mathrm{C}$, latitude squared $(\beta=-1.4 ; P<0.01)$, latitude cubed ( $\beta=-0.028 ; P<0.05)$, longitude $(\beta=2022 ; P<0.01)$, longitude squared $(\beta=-135 ; P<0.01)$, longitude cubed $(\beta=0.3 ; P<0.01)$, PC1 $(\beta=-8.9 ; P<0.01)$, PC2 $(\beta=-1.8$; $P<0.01)$ and PC4 $(\beta=-9.9 ; P<0.01)$ explained $58 \%$ of the variation in $\mathrm{Hsp} 70$ expression (Table 2). At $39^{\circ} \mathrm{C}$, latitude $(\beta=25 ; P<0.01)$, PC1 $(\beta=-12 ; P<0.05)$, PC2 $(\beta=-32 ; P<0.01)$ and PC4 $(\beta=-8.8 ; P<0.05)$ explained $31 \%$ of the variation in female Hsp70 expression (Table 2). For Hsp70 expression in males at $37^{\circ} \mathrm{C}$, latitude $(\beta=298$; $P<0.01)$, latitude squared $(\beta=8.3 ; P<0.05)$, latitude

Table 1 Means and SE for all traits measured

\begin{tabular}{|c|c|c|c|c|c|c|c|c|c|c|c|c|c|c|c|c|c|c|c|}
\hline \multirow[t]{3}{*}{ Pop } & \multicolumn{6}{|c|}{ Hsp70 expression (abs) } & \multirow[t]{3}{*}{$K D(s)$} & \multicolumn{2}{|c|}{ Sterility $(h)$} & \multicolumn{4}{|c|}{ Developmental time $(h)$} & \multicolumn{6}{|c|}{ Heat-shock survival rate } \\
\hline & \multirow{2}{*}{$\begin{array}{c}\text { Larvae } \\
37^{\circ} \mathrm{C}\end{array}$} & \multirow{2}{*}{$\begin{array}{c}\text { Pupae } \\
38^{\circ} \mathrm{C}\end{array}$} & \multicolumn{2}{|c|}{$q$} & \multicolumn{2}{|c|}{$\hat{0}$} & & \multirow[b]{2}{*}{$25^{\circ} \mathrm{C}$} & \multirow[b]{2}{*}{$38^{\circ} \mathrm{C}$} & \multicolumn{2}{|c|}{ q } & \multicolumn{2}{|c|}{$0^{t}$} & \multicolumn{2}{|c|}{ Larvae } & \multicolumn{2}{|c|}{$q$} & \multicolumn{2}{|c|}{$\sigma$} \\
\hline & & & $37^{\circ} \mathrm{C}$ & $38^{\circ} \mathrm{C}$ & $37^{\circ} \mathrm{C}$ & $38^{\circ} \mathrm{C}$ & & & & $25^{\circ} \mathrm{C}$ & $30^{\circ} \mathrm{C}$ & $25^{\circ} \mathrm{C}$ & $30^{\circ} \mathrm{C}$ & No $H$ & $H$ & No $H$ & $H$ & No $H$ & $H$ \\
\hline Mub & 0.34 & 0.047 & 0.30 & 0.71 & 0.16 & 0.43 & 124 & 48 & 111 & 316 & 274 & 318 & 289 & 0.46 & 0.51 & 0.74 & 0.72 & 0.45 & 0.53 \\
\hline SE & 0.1 & 0.02 & 0.07 & 0.2 & 0.04 & 0.1 & 21 & 4 & 14 & 3 & 3 & 3 & 4 & 0.08 & 0.07 & 0.07 & 0.06 & 0.1 & 0.1 \\
\hline Isg & 0.37 & 0.042 & 0.40 & 0.78 & 0.39 & 0.55 & 70 & 38 & 99 & 308 & 282 & 309 & 281 & 0.38 & 0.31 & 0.75 & 0.74 & 0.41 & 0.65 \\
\hline SE & 0.06 & 0.01 & 0.06 & 0.1 & 0.1 & 0.04 & 8 & 2 & 13 & 3 & 4 & 2 & 4 & 0.08 & 0.08 & 0.05 & 0.08 & 0.08 & 0.07 \\
\hline Bwc & 0.41 & 0.054 & 0.22 & 0.65 & 0.10 & 0.40 & 68 & 43 & 84 & 333 & 296 & 336 & 300 & 0.54 & 0.56 & 0.94 & 0.80 & 0.63 & 0.64 \\
\hline SE & 0.07 & 0.01 & 0.04 & 0.2 & 0.01 & 0.07 & 9 & 4 & 19 & 3 & 4 & 5 & 5 & 0.08 & 0.1 & 0.02 & 0.06 & 0.09 & 0.07 \\
\hline Grd & 0.35 & 0.053 & 0.13 & 0.35 & 0.14 & 0.27 & 75 & 40 & 120 & 313 & 287 & 311 & 288 & 0.57 & 0.38 & 0.69 & 0.82 & 0.50 & 0.67 \\
\hline SE & 0.05 & 0.009 & 0.02 & 0.1 & 0.03 & 0.05 & 10 & 2 & 8 & 4 & 4 & 2 & 3 & 0.09 & 0.08 & 0.09 & 0.06 & 0.1 & 0.07 \\
\hline His & 0.34 & 0.023 & 0.46 & 0.92 & 0.26 & 0.63 & 60 & 43 & 104 & 313 & 270 & 310 & 283 & 0.34 & 0.41 & 0.61 & 0.74 & 0.44 & 0.53 \\
\hline SE & 0.06 & 0.009 & 0.04 & 0.2 & 0.03 & 0.08 & 6 & 2 & 7 & 3 & 4 & 2 & 4 & 0.08 & 0.06 & 0.07 & 0.06 & 0.06 & 0.08 \\
\hline Metz & 0.44 & 0.040 & 0.17 & 0.41 & 0.20 & 0.48 & 50 & 40 & 101 & 317 & 290 & 330 & 299 & 0.55 & 0.54 & 0.85 & 0.84 & 0.52 & 0.74 \\
\hline SE & 0.04 & 0.01 & 0.04 & 0.1 & 0.05 & 0.1 & 5 & 2 & 10 & 4 & 4 & 3 & 3 & 0.08 & 0.1 & 0.05 & 0.07 & 0.1 & 0.08 \\
\hline Bar & 0.37 & 0.036 & 0.26 & 0.75 & 0.10 & 0.56 & 61 & 41 & 108 & 311 & 289 & 314 & 305 & 0.53 & 0.41 & 0.91 & 0.78 & 0.41 & 0.69 \\
\hline SE & 0.1 & 0.001 & 0.06 & 0.2 & 0.002 & 0.01 & 12 & 2 & 11 & 3 & 4 & 3 & 5 & 0.08 & 0.08 & 0.04 & 0.09 & 0.1 & 0.05 \\
\hline Tam & 0.55 & 0.054 & 0.14 & 0.45 & 0.12 & 0.28 & 98 & 40 & 84 & 330 & 304 & 335 & 301 & 0.25 & 0.30 & 0.80 & 0.84 & 0.58 & 0.68 \\
\hline SE & 0.05 & 0.007 & 0.03 & 0.08 & 0.03 & 0.05 & 20 & 3 & 13 & 3 & 4 & 3 & 3 & 0.08 & 0.08 & 0.03 & 0.03 & 0.1 & 0.1 \\
\hline Ger & 0.50 & 0.057 & 0.33 & 0.40 & 0.09 & 0.26 & 55 & 36 & 93 & 310 & 290 & 311 & 284 & 0.61 & 0.39 & 0.42 & 0.73 & 0.43 & 0.63 \\
\hline SE & 0.08 & 0.02 & 0.09 & 0.08 & 0.01 & 0.03 & 6 & 2 & 18 & 4 & 5 & 3 & 4 & 0.06 & 0.1 & 0.08 & 0.05 & 0.09 & 0.1 \\
\hline Bul & 0.49 & 0.045 & 0.24 & 0.43 & 0.25 & 0.65 & 51 & 40 & 85 & 312 & 295 & 315 & 300 & 0.58 & 0.32 & 0.79 & 0.78 & 0.50 & 0.58 \\
\hline SE & 0.01 & 0.01 & 0.02 & 0.08 & 0.02 & 0.09 & 5 & 2 & 13 & 3 & 5 & 2 & 4 & 0.02 & 0.08 & 0.1 & 0.08 & 0.08 & 0.06 \\
\hline Mal & 0.51 & 0.027 & 0.18 & 0.56 & 0.24 & 0.35 & 68 & 36 & 67 & 315 & 278 & 320 & 296 & 0.38 & 0.29 & 0.76 & 0.67 & 0.40 & 0.48 \\
\hline SE & 0.02 & 0.008 & 0.02 & 0.07 & 0.07 & 0.08 & 17 & 4 & 12 & 4 & 4 & 2 & 6 & 0.05 & 0.08 & 0.07 & 0.09 & 0.06 & 0.09 \\
\hline
\end{tabular}

$\mathrm{KD}$, knockdown resistance; sterility, heat-induced male sterility. 
Table 2 Sign and significance level of the regressions of traits on latitude (lat), latitude squared (lat ${ }^{2}$ ), latitude cubed (lat $\left.{ }^{3}\right)$, longitude (long), longitude squared $\left(\mathrm{long}^{2}\right)$, longitude cubed $\left(\mathrm{long}^{3}\right)$, the first four principal components from a PCA of 35 climatic variables (PC1-4) and distance to coast (DSCT)

\begin{tabular}{|c|c|c|c|c|c|c|c|c|c|c|c|c|c|}
\hline Trait & HspL & Hspf37 & Hspf39 & Hspm37 & Hspm39 & $K D$ & Steril25 & Steril38 & $D m 25$ & $H S f$ & HHSm & HSL & HHSL \\
\hline $\begin{array}{l}\text { lat } \\
\text { lat }^{2} \\
\text { lat }^{3}\end{array}$ & $t^{* * *}$ & $\begin{array}{l}-^{* *} \\
-^{*}\end{array}$ & $+^{* *}$ & $\begin{array}{l}+^{* *} \\
+^{* *} \\
+^{*}\end{array}$ & $t^{* * *}$ & $-^{* *}$ & $+^{* *}$ & & $\begin{array}{l}+^{* * *} \\
+^{* * *}\end{array}$ & $\begin{array}{l}+^{* * *} \\
+^{* * *}\end{array}$ & $\begin{array}{l}-^{* *} \\
-^{* *}\end{array}$ & $\begin{array}{l}+^{* * *} \\
-^{* *} \\
+^{* * *}\end{array}$ & \\
\hline $\begin{array}{l}\text { long } \\
\text { long } \\
\text { long }\end{array}$ & & $\begin{array}{l}+^{* *} \\
-{ }^{* *} \\
+^{* *}\end{array}$ & & & $\begin{array}{l}+^{* * *} \\
-* * * \\
+^{* * *}\end{array}$ & & & $+^{*}$ & $-* * *$ & & & $\begin{array}{l}+^{* * *} \\
-^{* * *}\end{array}$ & $\begin{array}{l}-^{*} \\
+^{*} \\
-^{*}\end{array}$ \\
\hline $\begin{array}{l}\text { PC1 } \\
\text { PC2 } \\
\text { PC3 }\end{array}$ & & $\begin{array}{l}-* * \\
-^{* *}\end{array}$ & $\begin{array}{l}-^{*} \\
+^{* *}\end{array}$ & $\begin{array}{l}-^{* * * *} \\
+^{* * *}\end{array}$ & $\begin{array}{l}-^{* * *} \\
-^{* * *}\end{array}$ & $-^{*}$ & & & $\begin{array}{l}+^{* * * *} \\
+^{* * *} \\
+^{* *}\end{array}$ & & & $\begin{array}{l}+^{* *} \\
-{ }^{* *} \\
-^{* * *} \\
+^{* * *}\end{array}$ & $\begin{array}{l}+^{* *} \\
-^{*}\end{array}$ \\
\hline PC4 & & $-* *$ & $+^{* *}$ & $\begin{array}{l}-^{* * *} \\
{ }^{* * *}\end{array}$ & & & & & $Z_{* *}^{* *}$ & $+^{*}$ & $+^{*}$ & $+^{* * *}$ & $\begin{array}{l}+^{* *} \\
+^{* *}\end{array}$ \\
\hline $\begin{array}{l}\text { DSCT } \\
R^{2}\end{array}$ & $16 \%$ & $58 \%$ & $31 \%$ & $\begin{array}{l}-* * * \\
52 \%\end{array}$ & $49 \%$ & $14 \%$ & $5.6 \%$ & $7.5 \%$ & $\begin{array}{l}-{ }^{* *} \\
16 \%\end{array}$ & $28 \%$ & $11 \%$ & $22 \%$ & $\begin{array}{l}+* * \\
10 \%\end{array}$ \\
\hline
\end{tabular}

HspL, Hsp70 expression level in larvae; Hspf37, Hsp70 expression level in females at $37^{\circ} \mathrm{C}$; Hspf39, Hsp70 expression level in females at $39^{\circ} \mathrm{C}$; Hspm37, Hsp70 expression level in males at $37^{\circ} \mathrm{C}$; Hspm39, Hsp70 expression level in males at $39^{\circ} \mathrm{C}$; KD, knockdown resistance; Steril25, male sterility period at $25^{\circ} \mathrm{C}$; Steril 38 , male sterility period at $25^{\circ} \mathrm{C}(18 \mathrm{~h}) / 38^{\circ} \mathrm{C}(6 \mathrm{~h})$; dm 25 , male developmental time at $25^{\circ} \mathrm{C}$; Hsf, heat shock resistance without hardening in females; HSL, heat shock resistance without hardening in larvae; HHSm, heat shock resistance with hardening in males; HHSL, heat shock resistance with hardening in larvae. Not presented in this table are nonsignificant regressions for pupal Hsp70 expression, female developmental time at 25 and $30^{\circ} \mathrm{C}$, male developmental time at $30^{\circ} \mathrm{C}$, male heat-shock survival without hardening and female survival with hardening.

${ }^{*} P<0.05 ;{ }^{* *} P<0.01 ;{ }^{* * *} P<0.001$.

cubed $(\beta=0.076 ; P<0.05)$, PC1 $(\beta=-12 ; P<0.001)$, PC3 $(\beta=14 ; P<0.001)$, PC4 $(\beta=-26 ; P \ll 0.001)$ and distance to coast $(\beta=-0.25, P \ll 0.001)$ explained $52 \%$. At $39^{\circ} \mathrm{C}$, latitude $(\beta=26 ; P \ll 0.001)$, longitude $(\beta=3410 ; P<0.001)$, longitude squared $(\beta=-229 ; P<0.001)$, longitude cubed $(\beta=0.51 ; P<0.001)$, PC1 $(\beta=-15 ; P<0.001)$ and PC2 $(\beta=-37 ; P \ll 0.001)$ explained $49 \%$ (Table 2$)$.

\section{Knockup down resistance}

A two-way ANOVA showed no effect of sex and no significant population by sex interaction. However, the effect of population was significant (Table 3). Latitude $(\beta=-2.7 ; P<0.01)$ and PC3 $(\beta=-6.2 ; P<0.05)$ explained $14 \%$ of the variation in knockdown time (Table 2 ).

\section{Sterility period}

Two-way ANOVA showed no significant population by rearing temperature interaction. However, there was an effect on sterility period of both temperature and population (Table 3). Latitude squared explained $5.6 \%$ of the variation in the sterility period at $25^{\circ} \mathrm{C}(\beta=0.0077$; $P<0.01)$. In all, $7.5 \%$ of the variation in sterility period at $25 / 38^{\circ} \mathrm{C}(\beta=3.3 ; P<0.05)$ could be explained by longitude (Table 2). Figure 4 shows the relation between sterility period and latitude.

\section{Developmental time}

A three-way ANOVA showed no significant two or three-way interactions, but population, sex and environment all had significant effects on developmental time (Table 3).

Female developmental time showed no significant regressions at either temperature, nor did male developmental time at $30^{\circ} \mathrm{C}$. However, $16 \%$ of the variation in male developmental time at $25^{\circ} \mathrm{C}$ could be explained by latitude squared ( $\beta=3.22 ; P<0.001)$, latitude cubed $(\beta=0.067 ; \quad P<0.001), \quad$ longitude squared $(\beta=-0.12 ;$ $P<0.001), \quad$ PC1 $\quad(\beta=16 ; \quad P<0.001), \quad$ PC2 $\quad(\beta=27$; $P<0.001)$, PC3 $(\beta=8.1 ; P<0.01)$ and distance to coast $(\beta=-0.29 ; P<0.01)$ (Table 2$)$.

Heat-shock survival without hardening, adults A two-way ANOVA revealed no interaction between the effects of population and sex on survival after $1 \mathrm{~h}$ at $40.5^{\circ} \mathrm{C}$. However, the effects of both population and sex were significant (Table 3 ). Latitude squared $(\beta=0.0087 ; \quad P<0.001), \quad$ latitude cubed $(\beta=0.0002$; $P<0.001)$, longitude squared $(\beta=-0.00032 ; P \ll 0.001)$ and PC4 $(\beta=0.073 ; P<0.05)$ explained $28 \%$ of the variation in survival in females (Table 2). No significant regression was detected in male survival after heat shock.

Heat-shock survival with hardening, adults

A two-way ANOVA revealed no interaction between the effects of population and sex on survival after $1 \mathrm{~h}$ at $41.5^{\circ} \mathrm{C}$. The effect of sex was significant, but the effect of population was not (Table 3). However, latitude $(\beta=-0.3 ; \quad P<0.01), \quad$ latitude squared $(\beta=-0.0049$; $P<0.01)$ and PC4 $(\beta=0.064 ; P<0.05)$ explained $11 \%$ of the variation in male heat-shock survival (Table 2). No significant regression was detected in female survival after hardening and heat-shock.

Heat-shock resistance without hardening, larvae

For larval survival after heat shock, latitude $(\beta=28$; $P<0.001)$, latitude squared $(\beta=-0.86 ; P<0.001)$, latitude cubed $(\beta=0.0087 ; P<0.001)$, longitude squared $(\beta=0.08$; $P<0.001)$, longitude cubed $(\beta=-0.00036, P<0.001)$, PC1 $(\beta=0.19 ; \quad P<0.01), \quad$ PC2 $\quad(\beta=-0.36 ; \quad P<0.01), \quad$ PC3 $(\beta=-0.48 ; P<0.001)$ and PC4 $(\beta=0.53 ; P<0.001)$ ex- 
plained $22 \%$ of the variation in survival (Table 2, Figure 3b).

Heat-shock resistance with hardening, larvae

For larval survival after hardening and heat shock, longitude $(\beta=-782 ; P<0.05)$, longitude squared $(\beta=5.2$; $P<0.05)$, longitude cubed $(\beta=-0.012 ; P<0.05)$, PC1
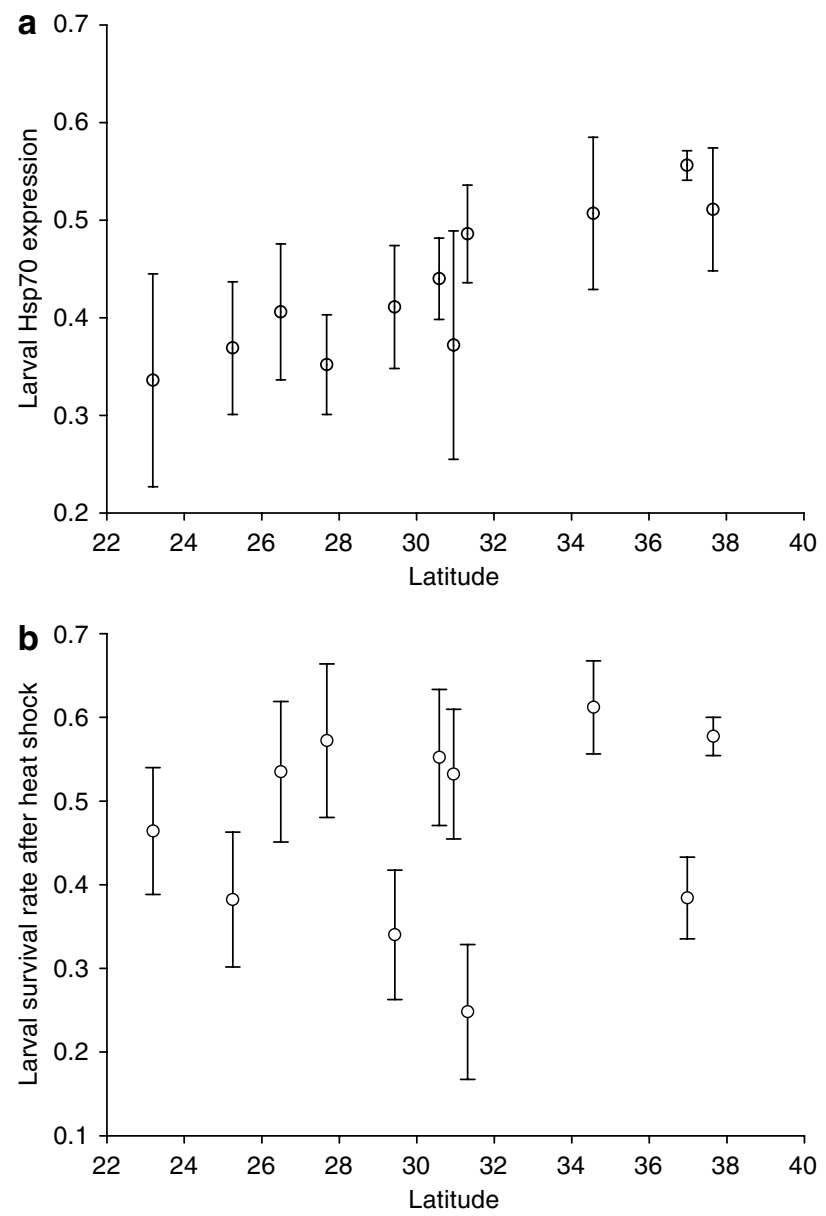

Figure 3 (a) Larval Hsp70 expression level after $1 \mathrm{~h}$ heat treatment at $37^{\circ} \mathrm{C}$ and then $1 \mathrm{~h}$ at $25^{\circ} \mathrm{C}$, plotted against latitude. Hsp70 expression level increases in lines collected at more southern sites, indicating that larvae from northern sites were less stressed by the heat treatment. (b) Survival after heat shock at $40.5^{\circ} \mathrm{C}$ for $1 \mathrm{~h}$ without hardening in larvae, plotted against latitude. $(\beta=0.19 ; \quad P<0.01), \quad$ PC2 $\quad(\beta=-0.15 ; \quad P<0.05), \quad$ PC4 $(\beta=0.44 ; \quad P<0.01)$ and distance to coast $(\beta=0.0085$; $P<0.01)$ explained $10 \%$ of the variation in survival (Table 2).

\section{Discussion}

We found clinal variation in 13 of the 19 traits studied (Table 2). Ten of these traits were influenced by several of the variables used in the analysis indicating a complex relationship between geographic coordinates, climatic variables and trait response, a fact that complicates interpretation. These traits also demonstrated simultaneous significant effects of both geographic coordinates and climatic variables (Table 2), meaning that important factors other than the climatic variables accounted for by ANUCLIM vary along latitudinal and/or longitudinal gradients. These factors might be variation in coexisting species (eg competitors, predators and food plants) or different frequencies of rare catastrophic events (eg droughts, fires).

The immobile life stage, pupae, showed no variation among populations in the one trait studied (Hsp70 expression level). The temperature tested induced only a low expression level in this comparably heat-resistant life stage (Krebs and Loeschcke, 1995b), but a higher

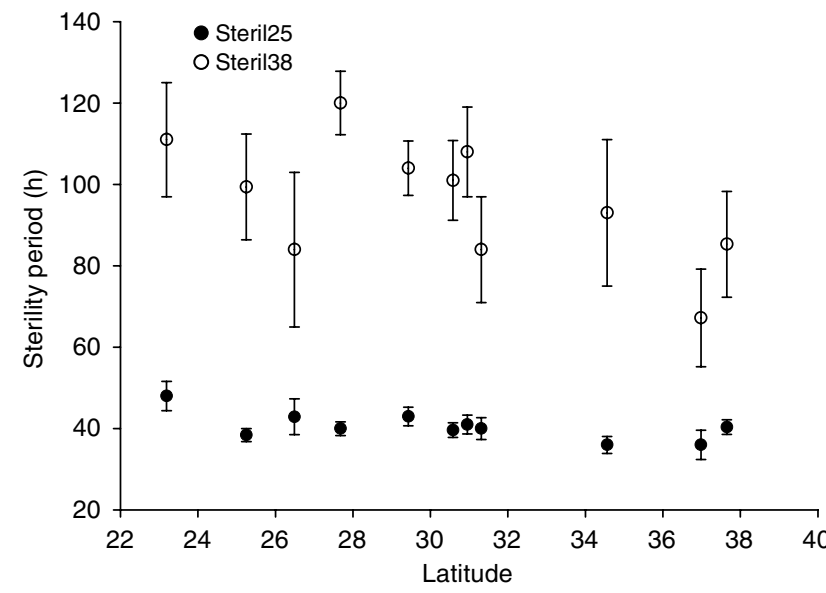

Figure 4 Plot of sterility period after development at $25^{\circ} \mathrm{C}$ (Steril25) or $25(18 \mathrm{~h}) / 38(6 \mathrm{~h})$ (Steril38) and transfer to $25^{\circ} \mathrm{C}$ at eclosure, plotted against latitude, showing longer sterility periods in lines originating from northern more heat-exposed localities.

Table 3 ANOVA results (mean squares) for tests of resistance in D. buzzatii from Australia, with degrees of freedom given in parentheses

\begin{tabular}{lcccc}
\hline Source & KD & Sterility & Dev. time & HS adults \\
\cline { 4 - 5 } & & & No H \\
\hline Pop (1) & $4690^{* *}(10)$ & $1119^{* *}(10)$ & $1678^{* *}(10)$ & $0.2^{* *}(10)$ \\
Sex (2) & $2103(1)$ & $1.4 \mathrm{E} 05^{* * *}(1)$ & $2383^{*}(1)$ & $9.6 \mathrm{E}-02(10)$ \\
Temp $(3)$ & & $749(10)$ & $6.5 \mathrm{E} 04^{* * *}(1)$ & $1.3^{* * *}(1)$ \\
$(1) \times(3)$ & & $321(10)$ & \\
$(1) \times(2)$ & & $239(10)$ & $9.7 \mathrm{E}-02(10)$ \\
$(2) \times(3)$ & & $280(1)$ & \\
$(1) \times(2) \times(3)$ & $1629(81)$ & $421(175)$ & $237(10)$ & $7.9 \mathrm{E}-02(10)$ \\
Error & & $597(374)$ & $6.3 \mathrm{E}-02(138)$
\end{tabular}

Traits are abbreviated as follows: KD, knock down; sterility, male sterility period; dev. time, developmental time; HS, heat shock; no H, without hardening; $\mathrm{H}$, with hardening.

${ }^{*} P<0.05 ;{ }^{* * P}<0.01 ; * * * P<0.001$ 
temperature might have revealed differences between populations. All larval traits investigated showed clinal variation (Figure 3), as did most adult traits (Table 2). Generally, a greater proportion of the variation in the adult traits could be explained by the environmental and geographic variables (higher $R^{2}$ ) than in the larval traits. This might be owing to larval samples containing a mixture of males and females, whereas the adults were separated according to sex. In adults, the sexes can differ in their response to heat stress (eg this study and Krebs and Loeschcke, 1995a; Sørensen et al, 2001; Norry et al, 2004), and this also may be the case in larvae. Although there are no striking visual differences between the sexes at this stage, high rearing temperatures can induce sterility in males when hatched but not in females. Thus, patterns specific to or differing between sexes might be reduced or overlooked because larvae were treated as a single unit.

As mentioned above, some studies have shown that different life stages and sexes differ in their reaction to heat stress. This is also the case in our study where males and females showed different response patterns in most traits. Only knockdown resistance did not display a significant effect of sex (Table 3 ). With regard to Hsp70 expression level, even though only two of the six measurements of Hsp70 expression level were correlated with each other, five of the six showed clinal variation confirming that the variation found between populations was not random. The independence of Hsp70 expression level between life stages and sexes is confirmed by the different pattern in the regressions (Table 2), for example, larval, adult female and male expression level at $37^{\circ} \mathrm{C}$ were all influenced by latitude squared, but opposed to larval and male expression, female Hsp70 expression level had a negative relation with latitude squared indicating lower Hsp70 expression at both high and low latitudes. As is seen in Figure 3a, larval Hsp70 expression showed a clear tendency towards higher levels in lines originating from colder environments. This pattern has previously been shown in adults (Sørensen et al, 2001; Zatsepina et al, 2001) and may indicate that the northern more heat-exposed populations were less affected by the Hsp70 inducing temperature.

Knockdown resistance is considered a very important heat resistance trait and clinal variation in this trait has been found in several studies, showing greater resistance in populations originating in warmer areas (for a review see Hoffmann et al, 2003a; Sørensen et al, 2005). In our study, knockdown time was affected negatively by both latitude and PC3, which means that knockdown resistance increases the further north a collection site is positioned. This is consistent with previous findings by Hoffmann et al (2002) in D. melanogaster, and suggests selection towards longer knockdown times in hot environments.

Earlier studies of $D$. buzzatii have found a prolonged duration of heat-induced male sterility in populations originating in hot environments (Vollmer et al, 2004). Rohmer et al (2004) found the opposite pattern in $D$. melanogaster. In the present study, northern populations had longer sterility periods than temperate populations, at least at $25^{\circ} \mathrm{C}$, confirming the previous findings in D. buzzatii (Table 2, Figure 4).

Developmental time has been found to vary with latitude in $D$. melanogaster, being slightly faster at high latitudes (James et al, 1995; James and Partridge, 1995).
In D. buzzatii, however, different studies have found increased (Bubliy and Loeschcke, 2005), unchanged (Loeschcke et al, 2000) and decreased developmental time (Norry et al, 2001) in flies originating from colder environments. In this study, only developmental time in males at $25^{\circ} \mathrm{C}$ showed clinal variation, but in a complex manner with developmental time related to both geographic and climatic variables.

Survival after a heat shock with or without prior hardening is an often-used measure of heat resistance. In D. buzzatii, some studies have found evidence of greater heat resistance in populations from hot environments (Krebs and Loeschcke, 1995a, b), whereas others did not (Sørensen et al, 2001, 2005). In this study, we found clinal variation in heat shock without hardening in adult females and larvae (Figure 3b), but not in males. However, in both life stages the proportion of the variation that was explained by the regressions was only half in hardened individuals compared to flies/larvae that were not hardened. Hardening seems to some degree to level out the differences between populations. The mechanism behind this might be that the flies most stressed by the hardening treatment had a higher activation of the heatshock response and thereby were comparably more protected against the following heat shock.

In many traits we see a significant effect of latitude squared, which might reflect a general response of the trait to stress, as both high and low latitudes could represent stressful conditions at the species boundaries. The collection sites span the whole distribution of $D$. buzzatii in Australia (Barker et al, 2005). The relations with latitude squared and cubed could be interpreted as a result of the joint effect of several evolutionary forces that vary differently along the gradient and therefore influence the traits in a complex manner. This complexity stems, among other things, from the fact that as latitude varies many climatic variables will vary simultaneously and most of them will be correlated. A correlation analysis of the 35 climatic variables provided by ANUCLIM (Houlder et al, 2000) revealed 33 correlations with $r>0.9$. Thus, significant and causal associations with individual climatic variables cannot be untangled by statistical analyses.

In conclusion, we found clinal variation in most traits studied, and in 10 of these, both geographic coordinates and climatic variables explained significant proportions of the variation (Table 2). As the principal components represent a combination of climatic variables, the results are not interpretable in terms of specific selection pressures. However, a few results are pointing in the expected direction, as for example the negative correlation of knockdown resistance with latitude discussed above. Moreover, this study shows indisputably that climate does influence the evolution of stress-related traits in both larvae and adults.

\section{Acknowledgements}

We are grateful to Doth Andersen and Mia F Nielsen for technical assistance, to $S$ Lindquist and $M$ Evgenev for kindly providing the 7FB antibody, to Ian Davies for statistical advice, and to the Danish Natural Sciences Research Council (frame and centre grant to VL) and the Faculty of Sciences, University of Aarhus (stipend to PS) for financial support. 


\section{References}

Akaike H (1974). A new look at the statistical model identification. IEEE Trans Automat Contr 19: 716-723.

Barker JSF, Krebs RA, Davies HI (2005). Geographical distributions, relative abundance and coexistence of Drosophila aldrichi and D. buzzatii in Australia. Austral Ecol 30: 546-557.

Barker JSF, Mulley JC (1976). Isozyme variation in natural populations of Drosophila buzzatii. Evolution 30: 213-233.

Bubliy OA, Loeschcke V (2005). Variation of life-history and morphometrical traits in Drosophila buzzatii and D. simulans collected along an altitudinal gradient from a Canary island. Biol J Linn Soc 84: 119-136.

Cossins AR, Bowler K (1987). Temperature Biology of Animals. Chapman \& Hall: New York.

Davidson JK (1990). Non-parallel geographic patterns for tolerance to cold and desiccation in Drosophila melanogaster and Drosophila simulans. Aust J Zool 38: 155-162.

Feder ME (1997). Necrotic fruit: a novel model system for thermal ecologists. J Therm Biol 22: 1-9.

Garland Jr T, Adolph SC (1994). Why not to do two-species comparative studies: limitations on inferring adaptation. Physiol Zool 67: 797-828.

Gibbs AG, Perkins MC, Markow TA (2003). No place to hide: microclimates of Sonoran Desert Drosophila. J Therm Biol 28 : 353-362.

Hoffmann AA, Anderson A, Hallas R (2002). Opposing clines for high and low temperature resistance in Drosophila melanogaster. Ecol Lett 5: 614-618.

Hoffmann AA, Hallas R, Sinclair C, Mitrovski P (2001). Levels of variation in stress resistance in Drosophila among strains, local populations, and geographic regions: patterns for desiccation, starvation, cold resistance, and associated traits. Evolution 55: 1621-1630.

Hoffmann AA, Hallas RJ, Dean JA, Schiffer M (2003b). Low potential for climatic stress adaptation in a rainforest Drosophila species. Science 301: 100-102.

Hoffmann AA, Sørensen JG, Loeschcke V (2003a). Adaptation of Drosophila to temperature extremes: bringing together quantitative and molecular approaches. J Therm Biol 28: 175-216.

Houlder DJ, Hutchinson MF, Nix HA, McMahon JP (2000). ANUCLIM User Guide, Version 5.1. Centre for Resource and Environmental Studies, Australian National University: Canberra.

Huey RB, Crill WD, Kingsolver JG, Weber KE (1992). A method for rapid measurement of heat or cold resistance of small insects. Funct Ecol 6: 489-494.

IPCC (2001). IPCC Working Group I Third Assessment Report, Climate Change 2001: The Scientific Basis (Summary for Policymakers); http://www.gcrio.org/OnLnDoc/pdf/ wg1spm.pdf.

James AC, Azevedo RBR, Partridge L (1995). Cellular basis and developmental timing in a size cline of Drosophila melanogaster. Genetics 140: 659-666.

James AC, Partridge L (1995). Thermal evolution of rate of larval development in Drosophila melanogaster in laboratory and field populations. J Evol Biol 8: 315-330.

JMP (2002). JMP for Windows, Version 5. SAS Institute Inc.: Cary, NC.

Karan D, Dahiya N, Munjal AK, Gibert P, Moreteau B, Parkash $\mathrm{R}$ et al (1998). Desiccation and starvation tolerance of adult Drosophila - opposite latitudinal clines in natural populations of three different species. Evolution 52: 825-831.

Krebs RA, Loeschcke V (1995a). Resistance to thermal stress in adult Drosophila buzzatii: Acclimation and variation among populations. Biol J Linn Soc 56: 505-517.
Krebs RA, Loeschcke V (1995b). Resistance to thermal stress in preadult Drosophila buzzatii: Variation among populations and changes in relative resistance across life stages. Biol J Linn Soc 56: 517-531.

Loeschcke V, Bundgaard J, Barker JSF (2000). Variation in body size and life history traits in Drosophila aldrichi and D. buzzatii from a latitudinal cline in eastern Australia. Heredity 85: 423-433.

Loeschcke V, Krebs RA (1996). Selection for heat-shock resistance in larval and in adult Drosophila buzzatii: comparing direct and indirect responses. Evolution 50: 2354-2359.

Loeschcke V, Krebs RA, Barker JSF (1994). Genetic variation for resistance and acclimation to high temperature stress in Drosophila buzzatii. Biol J Linn Soc 52: 83-92.

Nix H (1982). Environmental determinants of biogeography and evolution in Terra Australis. In: Barker WR, Greenslade PJM (eds) Evolution of the Flora and Fauna of Arid Australia. Peacock Publications: Frewville, SA, pp 47-66.

Norry FM, Bubliy OA, Loeschcke V (2001). Developmental time, body size and wing loading in Drosophila buzzatii from lowland and highland populations in Argentina. Hereditas 135: $35-40$

Norry FM, Dahlgaard J, Loeschcke V (2004). Quantitative trait loci affecting knockdown resistance to high temperature in Drosophila melanogaster. Mol Ecol 13: 3585-3594.

R Development Core Team (2003). R: A Language and Environment for Statistical Computing. R Foundation for Statistical Computing: Vienna, Austria, ISBN 3-900051-00-3; http:// www.R-project.org.

Rohmer C, David JR, Moreteau B, Joly D (2004). Heat induced male sterility in Drosophila melanogaster: adaptive genetic variations among geographic populations and role of the $\mathrm{Y}$ chromosome. J Exp Biol 207: 2735-2743.

SAS Institute (1985). SAS User's Guide: Statistics, Version 6. SAS Institute Inc.: Cary, NC.

Sokal RR, Rohlf FJ (1995). Biometry, 3rd edn. WH Freeman and Company: New York.

Sørensen JG, Dahlgaard J, Loeschcke V (2001). Genetic variation in thermal tolerance among natural populations of Drosophila buzzatii: down regulation of Hsp70 expression and variation in heat stress resistance traits. Funct Ecol 15: 289-296.

Sørensen JG, Kristensen TN, Loeschcke V (2003). The evolutionary and ecological role of heat shock proteins. Ecol Lett 6: 1025-1037.

Sørensen JG, Michalak P, Justesen J, Loeschcke V (1999). Expression of the heat-shock protein HSP70 in Drosophila buzzatii lines selected for thermal resistance. Hereditas 131: 155-164.

Sørensen JG, Norry FM, Scannapieco AC, Loeschcke V (2005). Altitudinal variation for stress resistance traits and thermal adaptation in adult Drosophila buzzatii from the New World. I Evol Biol 18: 829-837.

Velazquez JM, Didomenico BJ, Linquist S (1980). Intracellular localization of heat shock proteins in Drosophila. Cell 20: 679-690.

Velazquez JM, Sonoda S, Bugaisky G, Lindquist S (1983). Is the major Drosophila heat shock protein present in cells that have not been heat shocked? I Cell Biol 96: 286-290.

Vollmer JH, Sarup P, Kaersgaard CW, Dahlgaard J, Loeschcke V (2004). Heat and cold-induced male sterility in Drosophila buzzatii: genetic variation among populations for the duration of sterility. Heredity 92: 257-262.

Zatsepina OG, Velikodvorskaia VV, Molodtsov VB, Garbuz D, Lerman DN, Bettencourt BR et al (2001). A Drosophila melanogaster strain from sub-equatorial Africa has exceptional thermotolerance but decreased Hsp70 expression. J Exp Biol 204: 1869-1881. 